\title{
Pinhão-manso: Crescimento sob condições diferenciadas de irrigação e de adubação no semiárido nordestino
}

\author{
Clayton M. de Carvalho', Thales V. de A. Viana ${ }^{2}$, Albanise B. Marinho', \\ Luiz A. de Lima Júnior ${ }^{2} \&$ Manoel Valnir Júnior ${ }^{4}$
}

\begin{abstract}
RESUMO
Uma das alternativas para ocupação do espaço deixado pelo algodão no semiárido cearense é o cultivo do pinhão-manso (Jatropha curcas L.) visando à produção do biodiesel. Face ao exposto, realizou-se este trabalho de campo para avaliar os efeitos de diferentes lâminas aplicadas $(735,53 ; 963,30 ; 1.191,03 ; 1.418,82$ e 1.646,60 mm) e níveis de adubação nitrogenada $\left(0 ; 25 ; 50\right.$ e $\left.75 \mathrm{~kg} \mathrm{ha}^{-1} \mathrm{de} \mathrm{N}\right)$ no crescimento da cultura do pinhão-manso. Os dados referentes ao crescimento da fitomassa fresca epígea foram obtidos em sete diferentes épocas do ciclo da cultura $(30 ; 60 ; 90 ; 120 ; 150 ; 180$ e 210 dias após poda). De acordo com os resultados, a altura caulinar e a taxa de crescimento relativo em altura caulinar obtiveram comportamento linear e crescente com o incremento das lâminas aplicadas. A época de coleta influenciou não apenas os valores de altura, mas também de diâmetro caulinar obtendo-se, em ambas as variáveis, comportamento linear ao decorrer da condução do experimento. Houve um declínio nos valores da taxa de crescimento relativo em altura e no diâmetro caulinar causado pelos fatores climáticos (temperatura, umidade relativa, pluviosidade e evaporação) e pelo início da floração e formação de frutos.
\end{abstract}

Palavras-chave: Jatropha curcas L., irrigação localizada, biodiesel

\section{Jatropha: Growth under different conditions of irrigation and fertilization in the northeastern semiarid}

\begin{abstract}
One of the viable alternatives for the occupation of the space left by the cotton in the semiarid of Ceará is the cultivation of Jatropha curcas L. aiming the production of biodiesel. Thus, this study aimed to evaluate the effects of different levels of irrigation water (735.53,963.30, 1191.03, 1418.82 and $1646.60 \mathrm{~mm})$ and nitrogen fertilizer $\left(0,25,50\right.$ and $\left.75 \mathrm{~kg} \mathrm{~N} \mathrm{ha}^{-1}\right)$ on the growth of the Jatropha curcas L crop. The data regarding the growth of fresh biomass epigeal phytomass were obtained at seven different crop cycle times $(30,60,90,120,150,180$ and 210 days after pruning). According to the results, the stem height and the relative growth rate in stem height had a linear increase with the increase of water depths. The collection time influenced the values of height and stem diameter, resulting in both a linear behavior over the course of the experiment. There was a decline in the values of relative growth rate in height and stem diameter caused by climatic factors (temperature, relative humidity, rainfall and evaporation) and the onset of flowering and fruit formation.
\end{abstract}

Key words: Jatropha curcas L., localized irrigation, biodiesel 


\section{INTRODUÇÃO}

Com o declínio acentuado do cultivo do algodão, responsável pela base de sustentação dos municípios cearenses localizados no semiárido, a substituição desta cultura por outras adaptadas ao semiárido para a produção de biodiesel se apresenta como boa alternativa para a geração de renda do homem do campo. Segundo Silva et al. (2009b), o pinhão-manso vem sendo considerado uma das espécies promissoras para a produção de biodiesel no Brasil, visto suas características indicadoras de um balanço energético/econômico favorável.

É bem provável que o pinhão-manso tenha sua origem no Brasil. Atualmente, é encontrado em quase todas as regiões do planeta, em maior ocorrência nas regiões tropicais e temperadas e, em menor escala, nas regiões frias. Este fato se deve em razão da espécie ser exigente em insolação com alta resistência à seca, além de também ser muito adaptável às várias condições edafoclimáticas podendo ser cultivada desde o nordeste até São Paulo e Paraná (Arruda et al., 2004).

A literatura disponível sobre a cultura do pinhão-manso ainda é bastante escassa pois passou a ser objeto de maior interesse nos últimos anos, com a crise do petróleo e a preocupação com os impactos ambientais causados pelo uso de combustíveis fósseis e, ainda, pela possibilidade de serem usados os óleos vegetais como combustíveis (Nery et al., 2009; Oliveira et al., 2010).

Em regiões semiáridas, como o município de Crateús, $\mathrm{CE}$, a baixa pluviosidade e solos pobres no aspecto nutricional se apresentam como os principais responsáveis pela baixa produtividade de diversas culturas cultivadas para obtenção do óleo vegetal destinado à produção de biodiesel.

Segundo Roza (2010), um dos recursos tidos como críticos para viabilizar os programas sustentáveis é a água, o que torna necessários estudos a respeito da relação entre água e produção de biomassa para fins energéticos como, por exemplo, a produção de biodiesel a partir do pinhão-manso.

$\mathrm{Na}$ região semiárida os plantios comerciais são, muitas vezes, inviáveis sem o uso da irrigação, mas esta tecnologia ainda é pouco utilizada por produtores de pinhão-manso devido à sua maior onerosidade e falta de pesquisas que mostrem suas reais necessidades hídricas e viabilidade econômica. Desta forma, o uso da irrigação pode trazer grandes vantagens aumentando a produção, mantendo a oferta constante e melhorando o rendimento da matéria-prima para o biodiesel. Tais vantagens se consolidam principalmente com a utilização do sistema de irrigação tipo gotejamento que possui eficiência de uso da água em torno de 90 a $95 \%$, tendo em vista que, para a limitação da disponibilidade de água no semiárido fazem-se necessárias práticas de redução do seu uso (Lima Júnior, 2011).

Segundo Lacerda et al. (2009), o conteúdo de água no solo e a matéria orgânica influenciam no crescimento e no desenvolvimento da mamoneira proporcionando, nas suas taxas, aumento de crescimento e desenvolvimento e em sua produção de fitomassa.

Segundo Oliveira \& Beltrão (2010), o nitrogênio é o elemento mais importante dentre os nutrientes mais influentes para o desenvolvimento agrícola, sendo este o nutriente mineral de que a planta do pinhão-manso necessita em maior quantidade.
Ante o exposto, o objetivo desta pesquisa foi avaliar os efeitos de diferentes lâminas aplicadas e níveis de adubação nitrogenada no crescimento da cultura do pinhão-manso.

\section{Material e Métodos}

O trabalho de campo foi desenvolvido no período de setembro de 2008 a fevereiro de 2010, na área experimental da Fazenda Bandeira pertencente à Agroempresa Brasil Ecodiesel, situada no município de Crateús, no Estado do Ceará, com as coordenadas geográficas $05^{\circ} 23^{\prime} 25^{\prime}$ ' S, $40^{\circ} 57^{\prime} 38^{\prime \prime} \mathrm{O}$ e 717 $\mathrm{m}$ de altitude. O clima da região é o BSw'h', tropical quente semiárido, com máximo de chuvas no outono (fevereiro a maio), com precipitação pluviométrica média de $786,7 \mathrm{~mm}$ ano $^{-1}$, médias anuais da temperatura de $27,1^{\circ} \mathrm{C}$ e da umidade relativa do ar de 74\% (1971-2000).

A área total do experimento cultivada com o pinhão-manso foi de $3.750 \mathrm{~m}^{2}(75 \times 50 \mathrm{~m})$; o delineamento experimental adotado foi o de blocos ao acaso no esquema de parcelas subdivididas; os tratamentos foram compostos a partir da combinação de cinco lâminas de irrigação (parcelas) e quatro níveis de adubação nitrogenada (subparcelas) totalizando 20 tratamentos com três repetições.

As parcelas experimentais mediram $250 \mathrm{~m}^{2}(25 \times 10 \mathrm{~m})$, compostas de 4 subparcelas de $60 \mathrm{~m}^{2}(6 \times 10 \mathrm{~m})$, com duas fileiras de plantas espaçadas $3 \times 2 \mathrm{~m}$, totalizando 10 plantas por fileira. Cada bloco tinha uma área de $1.250 \mathrm{~m}^{2}(25 \times 50 \mathrm{~m})$. Na subparcela apenas uma fileira de plantas foi contabilizada como plantas úteis para obtenção de dados, sendo a outra fileira utilizada como bordadura comum entre subparcelas. Na fileira de plantas úteis também foram consideradas as plantas das extremidades como bordadura, ou seja, a primeira e a última planta de cada fileira; assim, das dez plantas somente as três plantas centrais de uma fileira foram contabilizadas como plantas úteis.

Cinco lâminas de irrigação foram aplicadas e definidas a partir da evaporação medida diariamente no tanque classe "A" cujos tratamentos foram: $\mathrm{L}_{1}=50 \%$ do total evaporado; $\mathrm{L}_{2}=$ $75 \%$ do total evaporado; $\mathrm{L}_{3}=100 \%$ do total evaporado; $\mathrm{L}_{4}=$ $125 \%$ do total evaporado e $\mathrm{L}_{5}=150 \%$ do total evaporado que, juntamente com a precipitação efetiva, resultaram nas lâminas aplicadas de 735,$53 ; 963,30 ; 1.191,03 ; 1.418,82$ e $1.646,60$ $\mathrm{mm}$, respectivamente.

A adubação foi diferenciada quanto à aplicação de nitrogênio e conforme recomendação do Laboratório de Solos e Água do Departamento de Ciências do Solo da Universidade Federal do Ceará $\left(50 \mathrm{~kg} \mathrm{ha}^{-1} \mathrm{de} \mathrm{N}\right)$ após a análise de solo. Os tratamentos utilizados foram de 0,50,100 e $150 \%$ do total recomendado, ou seja: $\mathrm{N}_{1}=0 \mathrm{~kg} \mathrm{ha}^{-1}$ de N; $\mathrm{N}_{2}=25 \mathrm{~kg} \mathrm{ha}^{-1}$ de N; $\mathrm{N}_{3}=50 \mathrm{~kg}$ ha $^{-1}$ de $\mathrm{N} \mathrm{e} \mathrm{N} \mathrm{N}_{4}=75 \mathrm{~kg} \mathrm{ha}^{-1}$ de N. Utilizaram-se $50 \mathrm{~kg} \mathrm{ha}^{-1} \mathrm{de}$ $\mathrm{P}$ e $50 \mathrm{~kg} \mathrm{ha}^{-1}$ de $\mathrm{K}$ para todos os tratamentos e, nos adubos: ureia (na proporção de $40 \%$ do total de $\mathrm{N}$ aplicado), sulfato de amônia (na proporção de $60 \%$ do total de $\mathrm{N}$ aplicado), cloreto de potássio e superfosfato simples, como fonte de nitrogênio $(\mathrm{N})$, enxofre $(\mathrm{S})$, fósforo $(\mathrm{P})$ e potássio $(\mathrm{K})$.

Foram selecionadas sete épocas de coleta: 30, 60, 90, 120, 150, 180 e 210 DAP (dias após poda de uniformização e início dos tratamentos de irrigação e adubação nitrogenada). 
Na Tabela 1 estão os parâmetros físico-hídricos e a caracterização química do solo determinados para a profundidade de 0 - 0,2 m da superfície do solo a partir de amostras compostas coletadas aleatoriamente na área em que o experimento foi implantado; os resultados da análise química serviram de base às adubações de fundação e de cobertura ao longo do ciclo da cultura.

Tabela 1. Caracterização físico-hídrica e química do solo da área experimental

\begin{tabular}{|c|c|c|}
\hline \multirow{2}{*}{ Parâmetro } & \multirow{2}{*}{ Unidade } & Profundidade (m) \\
\hline & & 0,20 \\
\hline \multicolumn{3}{|c|}{ Físico-hídrica } \\
\hline Areia grossa & $\mathrm{g} \mathrm{kg}^{-1}$ & 615 \\
\hline Areia fina & $\mathrm{g} \mathrm{kg}^{-1}$ & 307 \\
\hline Silte & $\mathrm{g} \mathrm{kg}^{-1}$ & 49 \\
\hline Argila & $\mathrm{g} \mathrm{kg}^{-1}$ & 29 \\
\hline Argila natural & $\mathrm{g} \mathrm{kg}^{-1}$ & 17 \\
\hline Densidade do solo & $\mathrm{kg} \mathrm{dm}^{-3}$ & 1,54 \\
\hline Densidade das partículas & $\mathrm{kg} \mathrm{dm}^{-3}$ & 2,66 \\
\hline Porosidade total & $\%$ & 41 \\
\hline Capacidade de campo* & $\mathrm{g} \mathrm{kg}^{-1}$ & 132,40 \\
\hline Ponto de murcha permanente ${ }^{\star}$ & $\mathrm{g} \mathrm{kg}^{-1}$ & 52,70 \\
\hline Água disponível & $\mathrm{g} \mathrm{kg}^{-1}$ & 79,70 \\
\hline Classe textural & & Areia \\
\hline \multicolumn{3}{|c|}{ Química } \\
\hline Matéria orgânica & $\mathrm{g} \mathrm{kg}^{-1}$ & 5,17 \\
\hline Cálcio & $\mathrm{cmol}_{\mathrm{c}} \mathrm{dm}^{-3}$ & 1,40 \\
\hline Magnésio & $\mathrm{cmol}_{\mathrm{c}} \mathrm{dm}^{-3}$ & 1,40 \\
\hline Cálcio + Magnésio & $\mathrm{cmol}_{\mathrm{C}} \mathrm{dm}^{-3}$ & 2,80 \\
\hline Alumínio & $\mathrm{cmol}_{\mathrm{c}} \mathrm{dm}^{-3}$ & 1,00 \\
\hline Potássio & $\mathrm{mg} \mathrm{dm}{ }^{-3}$ & 31,00 \\
\hline Fósforo & $\mathrm{mg} \mathrm{dm}^{-3}$ & 5,00 \\
\hline Sódio & $\mathrm{mg} \mathrm{dm} \mathrm{m}^{-3}$ & 3,00 \\
\hline $\mathrm{pH}$ & & 4,50 \\
\hline
\end{tabular}

* As umidades na capacidade de campo e ponto de murcha permanente foram determinadas pelo método do anel volumétrico nos potenciais de $-0,010 \mathrm{MPa}$ e $-1,5 \mathrm{MPa}$, respectivamente

Ao término do período chuvoso de 2009, mais precisamente no fim do mês de julho (194 dias após o transplantio), foi realizada uma poda de uniformização em todas as plantas deixando-as com altura de $0,3 \mathrm{~m}$, para posteriormente serem iniciados os tratamentos com as lâminas de irrigação e os níveis de adubação nitrogenada.

Adotou-se o sistema de irrigação localizado por gotejamento da PLASTO ${ }^{\circledR}$, trabalhando com uma pressão média de $20 \mathrm{kPa}$ e vazão nominal de $8 \mathrm{~L} \mathrm{~h}^{-1}$, espaçados $2 \mathrm{~m}$ sendo um emissor para cada planta, a uma distância de $0,10 \mathrm{~m}$ do caule.

As lâminas de irrigação aplicadas nos tratamentos foram controladas por registros de linha, conforme o tempo de irrigação diário quantificado a partir da evaporação medida no tanque Classe "A", conforme Eq. 1.

$$
\mathrm{Ti}=\frac{(\mathrm{f} \times \mathrm{ECA} \times \mathrm{El} \times \mathrm{Ep} \times \mathrm{FC})}{(\mathrm{Ei} \times \mathrm{Qg})}
$$

em que:

Ti - tempo de irrigação, em h

f - fator de ajuste em conformidade com os tratamentos utilizados

ECA - evaporação medida no tanque classe "A", em mm d ${ }^{-1}$

El - espaçamento entre linhas de plantas, em $\mathrm{m}$
Ep - espaçamento entre plantas, em m

$\mathrm{Fc}$ - fator de cobertura do solo, adimensional

Ei - eficiência de irrigação, adimensional (valor adotado de $90 \%$, obtido através de avaliações em campo do sistema utilizado)

Qg - vazão dos gotejadores por planta, em $\mathrm{L} \mathrm{h}^{-1}$

Como a quantidade de água aplicada foi determinada mediante as leituras diretas da evaporação diária através de um tanque evaporímetro Classe "A"; é oportuno ressaltar que a utilização deste método, embora menos preciso do que os métodos diretos de estimativa da evapotranspiração, como no caso do lisímetro, é justificada pela simplicidade de seu uso através do pequeno produtor.

A caracterização do crescimento do pinhão-manso foi realizada utilizando-se o estudo da fitomassa fresca epígea através do método da análise clássica não destrutiva. As variáveis do estudo da fitomassa fresca foram avaliadas mensalmente conforme já descrito. As variáveis avaliadas foram:

- Altura caulinar da planta (AC), em cm, determinada através de medições da altura da planta com a utilização de uma trena, desde a superfície do solo até a dominância apical.

- Diâmetro caulinar (DC), em mm, determinado com o auxílio de um paquímetro digital verificando-se o diâmetro aos $5 \mathrm{~cm}$ em relação à superfície do solo.

- Taxa de crescimento relativo em altura caulinar (TCRC), em $\mathrm{cm} \mathrm{cm}^{-1} \mathrm{~d}^{-1}$ determinada pela Eq. 2.

$$
\operatorname{TCRC}=\frac{\left[\log \left(\mathrm{H}_{2}\right)-\log \left(\mathrm{H}_{1}\right)\right]}{\left(\mathrm{T}_{2}-\mathrm{T}_{1}\right)}
$$

em que:

TCRC - taxa de crescimento relativo em altura caulinar, em cm cm ${ }^{-1} \mathrm{~d}^{-1}$

$\mathrm{H}$ - altura (em dois períodos distintos), em $\mathrm{cm}$

$\mathrm{T}$ - tempo (em dois tempos distintos), em dias

- Taxa de crescimento relativo em diâmetro caulinar (TCRDC), em $\mathrm{mm} \mathrm{mm}^{-1} \mathrm{~d}^{-1}$, determinada pela Eq. 3 .

$$
\mathrm{TCRDC}=\frac{\left[\log \left(\mathrm{D}_{2}\right)-\log \left(\mathrm{D}_{1}\right)\right]}{\left(\mathrm{T}_{2}-\mathrm{T}_{1}\right)}
$$

em que:

TCRDC - taxa de crescimento relativo em diâmetro caulinar, em $\mathrm{mm} \mathrm{mm}^{-1} \mathrm{~d}^{-1}$

D - diâmetro (em dois períodos distintos), em mm

$\mathrm{T}$ - tempo (em dois tempos distintos), em dias

- Taxa de crescimento relativo em fitomassa fresca epígea (TCRFFE), em $\mathrm{cm}^{3} \mathrm{~cm}^{-3} \mathrm{~d}^{-1}$, determinada pela Eq. 4.

$$
\text { TCRFFE }=\frac{\left[\log \left(\mathrm{H}_{2}\right) \mathrm{D}_{2}^{2}-\log \left(\mathrm{H}_{1}\right) \mathrm{D}_{1}^{2}\right]}{\left(\mathrm{T}_{2}-\mathrm{T}_{1}\right)}
$$

em que:

TCRFFE - taxa de crescimento relativo em fitomassa fresca epígea, em $\mathrm{cm}^{3} \mathrm{~cm}^{-3} \mathrm{~d}^{-1}$ 
$\mathrm{H}$ - altura (em dois períodos distintos), em $\mathrm{cm}$

D - diâmetro (em dois períodos distintos), em $\mathrm{cm}$

$\mathrm{T}$ - tempo (em dois tempos distintos), em dias

Os dados foram submetidos à análise de variância (Anova); posteriormente, quando os dados foram significativos pelo teste $\mathrm{F}$, os efeitos das lâminas de irrigação e dos níveis de adubação nitrogenada foram submetidos à análise de regressão buscando-se ajustar equações com significados biológicos; no caso de efeitos significativos entre a interação de dois ou mais fatores (lâminas de irrigação, níveis de adubação nitrogenada e épocas de coleta) foram realizadas as superfícies de resposta. $\mathrm{Na}$ análise de regressão as equações que melhor se ajustaram aos dados foram escolhidas com base na significância dos coeficientes de regressão a 1 e $5 \%$ de probabilidade pelo teste F e no maior coeficiente de determinação $\left(\mathrm{R}^{2}\right)$; os estudos da análise de variância e análise de regressão foram realizados com o auxílio de planilhas eletrônicas do Excel utilizando-se o software Assistat 7.5 Beta; enfim, para a confecção dos gráficos e determinação das equações de superfícies de resposta foi utilizado o software "TableCurve3D v.4.0"

\section{Resultados e Discussão}

Os dados da altura e do diâmetro caulinar referentes ao período de condução do experimento (210 DAP) foram aglutinados na Tabela 2 .

Tabela 2. Resumo das análises de variância para a altura caulinar (AC) e diâmetro caulinar (DC) em função das lâminas de irrigação, das doses de nitrogênio e das épocas de coleta

\begin{tabular}{|c|c|c|c|}
\hline \multirow{2}{*}{$\begin{array}{l}\text { Fonte de } \\
\text { variação }\end{array}$} & \multirow{2}{*}{ GL } & \multicolumn{2}{|c|}{ Quadrado médio } \\
\hline & & $A C(\mathrm{~cm})$ & DC (mm) \\
\hline Lâmina de irrigação (L) & 4 & $4.927,51637^{* *}$ & $345,54300^{\text {ns }}$ \\
\hline Regressão linear & 1 & $1.309,82629^{* *}$ & - \\
\hline Regressão quadrática & 1 & $282,74420^{\star \star}$ & - \\
\hline Regressão cúbica & 1 & $3,3644^{\text {ns }}$ & - \\
\hline Níveis de nitrogênio (N) & 3 & $708,78849^{\text {ns }}$ & $74,39226^{\text {ns }}$ \\
\hline Época de coleta (E) & 6 & $53.341,91961^{* *}$ & $5.596,40320^{* \star}$ \\
\hline Regressão linear & 1 & $24.806,37961^{* *}$ & $2.692,91629^{* *}$ \\
\hline Regressão quadrática & 1 & $761,48615^{* *}$ & $7,28907^{\star *}$ \\
\hline Regressão cúbica & 1 & $463,66145^{* *}$ & $11,26081^{\star *}$ \\
\hline Interação L x N & 12 & $467,26638^{\text {ns }}$ & $99,93542^{\text {ns }}$ \\
\hline Interação L x E & 24 & $229,21624^{\star \star}$ & $6,55890^{\text {ns }}$ \\
\hline Interação N x E & 18 & $62,40787^{\text {ns }}$ & $3,12184^{\mathrm{ns}}$ \\
\hline Interação L x N x E & 72 & $30,40814^{\mathrm{ns}}$ & $5,08727^{\text {ns }}$ \\
\hline Bloco & 2 & $2.507,12318^{\text {ns }}$ & $131,57147^{\text {ns }}$ \\
\hline Resíduo (L) & 8 & 684,70888 & 190,25860 \\
\hline Resíduo (N) & 30 & 540,42983 & 91,02201 \\
\hline Resíduo (E) & 240 & 42,12881 & 5,67032 \\
\hline CV $(\mathrm{L})$ & $(\%)$ & 32,95 & 20,76 \\
\hline CV $(N)$ & $(\%)$ & 29,27 & 14,36 \\
\hline CV $(E)$ & $(\%)$ & 8,17 & 3,58 \\
\hline
\end{tabular}

${ }^{\left.{ }^{* \star}\right)}$ Efeito significativo a 0,01 e $\left(^{*}\right)$ a 0,05 de probabilidade; ( ${ }^{\text {ns })}$ não significativo a nível de 0,05 de probabilidade pelo teste $\mathrm{F}$

Efeitos negativos no desenvolvimento da altura e do diâmetro caulinar da planta em condições de estresse hídrico ocorrem devido a um declínio no crescimento celular, efeito este encontrado também por Roza (2010) ao constatar uma redução de $128 \mathrm{~cm}$ para $47 \mathrm{~cm}$ na altura caulinar.
Com base nos resultados obtidos da análise de variância apresentados na Tabela 2 observa-se que houve efeito significativo a nível de $1 \%$ de probabilidade das lâminas aplicadas (L) e da época de coleta dos dados (E) tal como também da interação desses dois fatores ( $\mathrm{L}$ x E) sobre a altura caulinar das plantas; não houve efeito significativo para as doses de $\mathrm{N}$ utilizadas neste trabalho de campo sobre nenhuma variável de crescimento do pinhão-manso.

Faria et al. (2011) constataram que o tratamento irrigado influenciou a altura das plantas de pinhão-manso em todos os períodos analisados e que os tratamentos de adubação não influenciaram esta característica da planta.

O melhor modelo de ajuste para a variável altura caulinar foi a regressão linear, conforme a equação da Figura 1A, apresentando tendência crescente com o incremento das lâminas baseadas na evaporação do tanque Classe "A" (ECA). O comportamento linear com o incremento na lâmina de irrigação aplicada também foi obtido por Silva et al. (2009a) estudando o efeito do estresse hídrico na cultura do pinhãomanso, por Albuquerque et al. (2009) avaliando o crescimento do pinhão-manso submetido a diferentes níveis de água e por Lima Júnior (2011) estudando o efeito da suspensão hídrica do desenvolvimento do pinhão-manso em Crateús, CE.

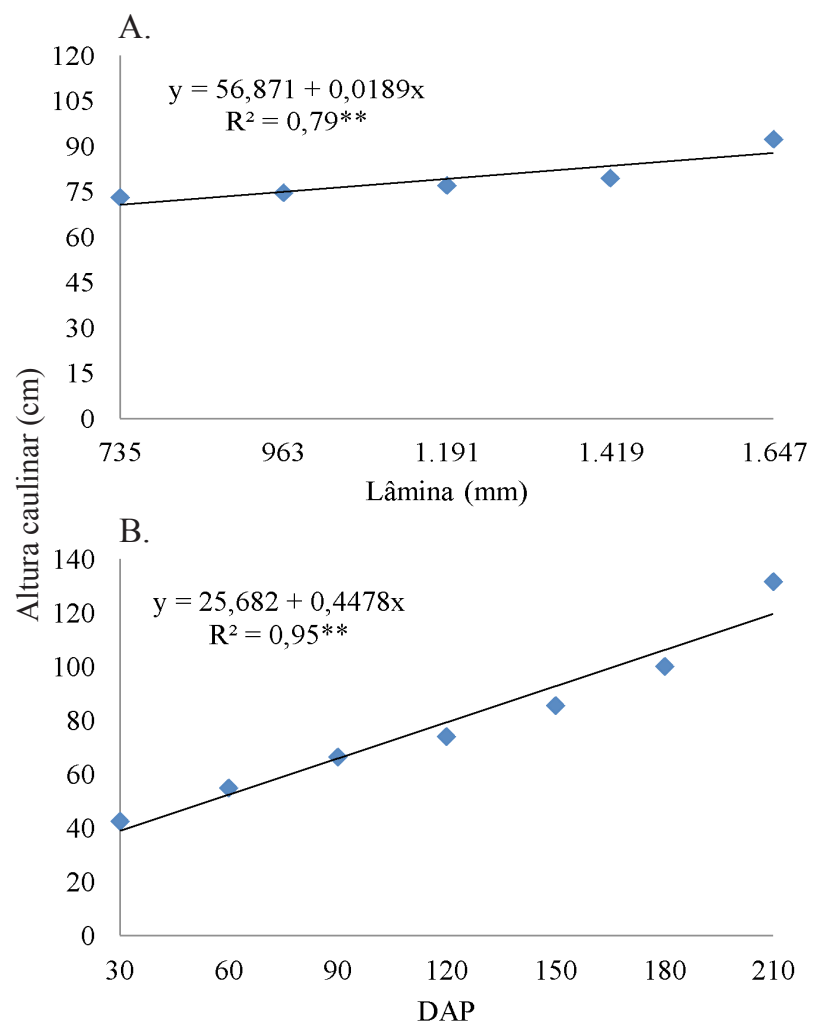

Figura 1. Altura caulinar do pinhão-manso, em função da lâmina de água $(\mathrm{A})$ e épocas de coleta (B)

Houve um aumento na altura caulinar de $73,16 \mathrm{~cm}$ no tratamento de menor lâmina aplicada $\left(\mathrm{L}_{1}=735,53 \mathrm{~mm}\right)$ até $92,42 \mathrm{~cm}$ na maior lâmina aplicada $\left(\mathrm{L}_{5}=1.646,61 \mathrm{~mm}\right)$, representando um incremento de $26,33 \%$.

Albuquerque et al. (2009) observaram, avaliando o crescimento do pinhão-manso em função de níveis de água e adubação nitrogenada em vasos, que a planta obteve melhores 
resultados para as variáveis de crescimento quando submetidas à maior dose de nitrogênio e ao maior nível de água disponível no solo. Silva et al. (2009a) concluíram, em seu experimento em vasos, que o estresse hídrico afetou a altura caulinar do pinhãomanso nos cinco períodos estudados (144, 186, 228, 270 e 312 dias após o transplantio), ocorrendo decréscimo significativo a nível de 0,01 de probabilidade nas variáveis.

Ressalta-se que o crescimento vigoroso da cultura não é conveniente haja vista que, segundo Laviola \& Dias (2008), pode ocorrer queda da produtividade em razão da demanda de nutrientes pelas partes vegetativas e autossombreamento e, ainda, dificultar a execução dos tratos culturais e fitossanitários e a operação de colheita. Os mesmos autores comentam também que a altura média das plantas, quando adultas, não deve ultrapassar dois metros.

No decorrer das diferentes épocas de coleta a altura caulinar apresenta um comportamento linear quando a planta partiu de uma altura média de $42,73 \mathrm{~cm}$ aos 30 DAP para 130,52 $\mathrm{cm}$ ao final do experimento, aos 210 DAP, representando um incremento de 205,45\% (Figura 1B). Segundo Arruda et al. (2004), o pinhão-manso apresenta crescimento rápido atingindo a altura de dois a três metros quando adulto e podendo alcançar até $5 \mathrm{~m}$ em condições especiais.

Verifica-se, na Figura 1, que os valores médios da altura caulinar das plantas de pinhão-manso para as lâminas de irrigação aplicadas e as diferentes épocas de coleta de dados tiveram altos coeficientes de determinação, o que garante uma correlação entre as variáveis estudadas.

No que se refere à interação entre os fatores lâmina e época de coleta ( $\mathrm{L}$ x E) houve um comportamento crescente em que a planta partiu de uma altura média de $40,92 \mathrm{~cm}$ com a lâmina aplicada de $735,53 \mathrm{~mm}$ aos 30 DAP para $153,10 \mathrm{~cm}$ com a lâmina de 1.646,61 mm aos 210 DAP obtendo-se, assim, um incremento de 274,15\% (Figura 2).

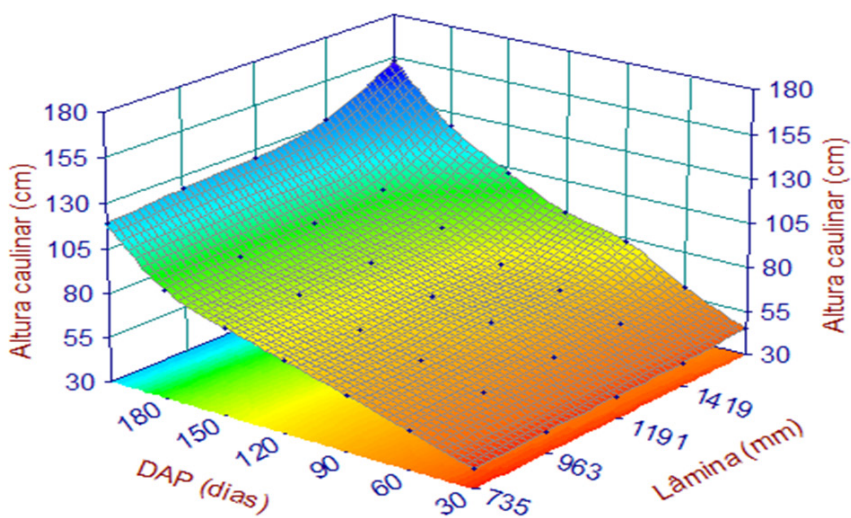

Figura 2. Altura caulinar do pinhão-manso, em função da interação entre lâmina de água e época de coleta (DAP - dias após a poda de uniformização)

Os valores se elevaram desde os 30 DAP no tratamento com a menor lâmina aplicada até os 210 DAP no tratamento com a maior lâmina aplicada. Tal tendência reforça os comentários de Santos (2008), Arruda et al. (2004) e Ratree (2004) acerca do rápido desenvolvimento do pinhão-manso e da problemática do déficit hídrico.

O resultado é concordante com Laime et al. (2009) ao afirmarem que o crescimento das plantas de pinhão-manso evolui de acordo com as épocas de avaliação e com o incremento dos níveis de reposição de água.

Para a superfície de resposta apresentada na Figura 2 foram geradas 566 equações e entre elas foi selecionada a melhor equação polinomial de segundo grau (Eq. 5) no que se refere ao valor do coeficiente de determinação $\left(\mathrm{R}^{2}\right)$ e a significância dos parâmetros componentes da equação.

$$
\begin{aligned}
\mathrm{z} & =96,326^{* *}-\frac{119.065,524^{* *}}{\mathrm{x}}+ \\
& +0,2372 \mathrm{y}^{*}+\frac{0,00000602^{* *}}{\mathrm{x}^{2}}+ \\
& +0,0015 \mathrm{y}^{2 * *}-\frac{167,569 \mathrm{y}^{* *}}{\mathrm{x}}
\end{aligned}
$$

(**) - efeito significativo a 0,01 de probabilidade

(*) - efeito significativo a 0,05 de probabilidade em que:

Z - altura caulinar, em cm

x - lâmina aplicada, em mm

y - época de coleta de dados (DAP), em dias

O coeficiente de determinação encontrado para a equação acima foi igual a 0,97 indicando um alto grau de associação entre a interação das lâminas aplicadas e as épocas de coleta da altura caulinar das plantas de pinhão-manso.

Conforme o resumo da análise de variância apresentado na Tabela 2, ocorreu efeito a nível de $1 \%$ de probabilidade no diâmetro caulinar, apenas na época de coleta $(\mathrm{E})$.

Segundo o modelo de regressão obtido no fator época de coleta, houve um comportamento idêntico ao acontecido com a variável altura caulinar, ou seja, ocorreu um comportamento linear e o diâmetro caulinar médio da planta aumentou de 53,42 $\mathrm{mm}$ aos 30 DAP para $81,49 \mathrm{~mm}$ ao final do experimento, aos 210 DAP representando um incremento de 65,55\% (Figura 3).

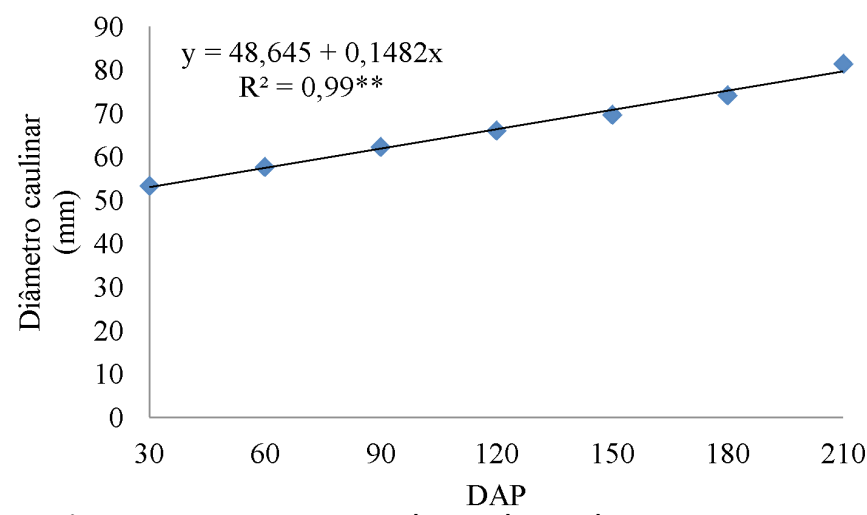

Figura 3. Diâmetro caulinar do pinhão-manso, em função da época de coleta (DAP - dias após a poda de uniformização)

Silva et al. (2009a) encontraram comportamento linear no aumento do diâmetro caulinar do pinhão-manso em diferentes épocas de cultivo submetido a tratamentos com estresse hídrico. Albuquerque et al. (2009) também encontraram resultado semelhante avaliando o crescimento do pinhão-manso em função do tempo quando submetido a níveis de água e adubação nitrogenada, e por Lima Júnior (2011) avaliando o efeito da 
suspensão hídrica no desenvolvimento do pinhão-manso em Crateús, CE.

Os dados referentes à taxa de crescimento relativo em altura caulinar, taxa de crescimento relativo em diâmetro caulinar e taxa de crescimento relativo em fitomassa fresca epígea referentes ao período de aplicação do experimento (210 DAP) foram aglutinados na Tabela 3.

Tabela 3. Resumo das análises de variância para a taxa de crescimento relativo em altura caulinar (TCR), taxa de crescimento relativo em diâmetro caulinar (TCRDC) e taxa de crescimento relativo em fitomassa fresca epígea (TCRFFE)

\begin{tabular}{|c|c|c|c|c|}
\hline \multirow{2}{*}{$\begin{array}{l}\text { Fonte de } \\
\text { variação }\end{array}$} & \multirow[b]{2}{*}{ GL } & \multicolumn{3}{|c|}{ Quadrado médio } \\
\hline & & $\begin{array}{c}\text { TCR } \\
\left(\mathrm{cm} \mathrm{cm}^{-1} \mathrm{~d}^{-1}\right)\end{array}$ & $\begin{array}{c}\text { TCRDC } \\
\left(\mathrm{mm} \mathrm{mm}^{-1} \mathrm{~d}^{-1}\right)\end{array}$ & $\begin{array}{c}\text { TCRFFE } \\
\left(\mathrm{cm}^{3} \mathrm{~cm}^{-3} \mathrm{~d}^{-1}\right)\end{array}$ \\
\hline Lâmina de irrigação (L) & 4 & $0,0000036^{*}$ & $0,0000039^{\text {ns }}$ & $0,05604^{\text {ns }}$ \\
\hline Regressão linear & 1 & $0,0000096^{*}$ & - & - \\
\hline Regressão quadrática & 1 & $0,0000013^{\text {ns }}$ & - & - \\
\hline Regressão cúbica & 1 & $0,0000002^{\text {ns }}$ & - & - \\
\hline Niveis de nitrogênio (N) & 3 & $0,0000004^{\text {ns }}$ & $0,0000005^{\text {ns }}$ & $0,02455^{\text {ns }}$ \\
\hline Época de coleta $(E)$ & 6 & $0,0000920^{* *}$ & $0,0000234^{\star *}$ & $2,73212^{\star *}$ \\
\hline Regressão linear & 1 & $0,000008^{* *}$ & $0,0000013^{\text {ns }}$ & $0,76171^{\star \star}$ \\
\hline Regressão quadrática & 1 & $0,000036^{\star \star}$ & $0,0000073^{\star *}$ & $0,42083^{* *}$ \\
\hline Regressão cúbica & 1 & $0,0000005^{\text {ns }}$ & $0,0000027^{\star}$ & $0,17038^{\star *}$ \\
\hline Interação L x N & 12 & $0,0000004^{\text {ns }}$ & $0,0000020^{\text {ns }}$ & $0,04309^{\text {ns }}$ \\
\hline Interação L x E & 24 & $0,0000016^{* *}$ & $0,0000056^{\star \star}$ & $0,04427^{\text {ns }}$ \\
\hline Interação N x E & 18 & $0,0000009^{\text {ns }}$ & $0,0000018^{\text {ns }}$ & $0,03180^{\text {ns }}$ \\
\hline Interação $L \times N$ x E & 72 & $0,0000003^{\star}$ & $0,0000019^{\text {ns }}$ & $0,03286^{\text {ns }}$ \\
\hline Bloco & 2 & $0,0000012^{\text {ns }}$ & $0,0000068^{*}$ & $0,17293^{\text {ns }}$ \\
\hline Resíduo (L) & 8 & 0,0000006 & 0,0000014 & 0,07142 \\
\hline Resíduo (N) & 30 & 0,0000005 & 0,0000024 & 0,04460 \\
\hline Resíduo (E) & 240 & 0,0000006 & 0,0000025 & 0,03682 \\
\hline $\mathrm{CV}(\mathrm{L})$ & $(\%)$ & 24,64 & 35,58 & 54,32 \\
\hline CV (N) & $(\%)$ & 22,85 & 47,00 & 42,93 \\
\hline CV (E) & (\%) & 24,76 & 47,77 & 39,00 \\
\hline
\end{tabular}

$\left.{ }^{* \star}\right)$ Efeito significativo a 0,01 e $\left(^{*}\right)$ a 0,05 de probabilidade; ( ${ }^{\text {ns }) ~ n a ̃ o ~ s i g n i f i c a t i v o ~ a ~ n i ́ v e l ~ d e ~}$ 0,05 de probabilidade pelo teste $F$

O resultado da análise de variância contido na Tabela 3 demonstra significância estatística em níveis de 0,01 e 0,05 de probabilidade para a variável taxa de crescimento relativo caulinar do pinhão-manso, o que mostra a resposta da cultura não só às lâminas aplicadas mas também às diferentes épocas de coleta, bem como a interação entre ambos.

Quanto à análise de regressão da taxa de crescimento relativo em altura caulinar em relação à lâmina aplicada, verificou-se que o modelo linear foi o que melhor se ajustou apresentando coeficiente de determinação de 0,87 (Figura 4A).

$\mathrm{O}$ mesmo comportamento linear e crescente da taxa de crescimento relativo caulinar foi encontrado por Lacerda et al. (2009) estudando a influência do déficit hídrico e da matéria orgânica do solo no crescimento e desenvolvimento da mamoneira BRS 188 - Paraguaçu. Os autores concluíram que as plantas cujos tratamentos foram submetidos aos maiores conteúdos de água do solo se apresentaram mais eficientes com relação à sua capacidade fotossintética.

Comparando a taxa de crescimento relativo em altura caulinar das plantas quando da aplicação da lâmina de $1.647 \mathrm{~mm}$ durante o período em estudo em relação à taxa de crescimento relativo caulinar das plantas que receberam lâmina aplicada de $735 \mathrm{~mm}$, ocorreu aumento de $17,59 \%$ evidenciando-se respostas

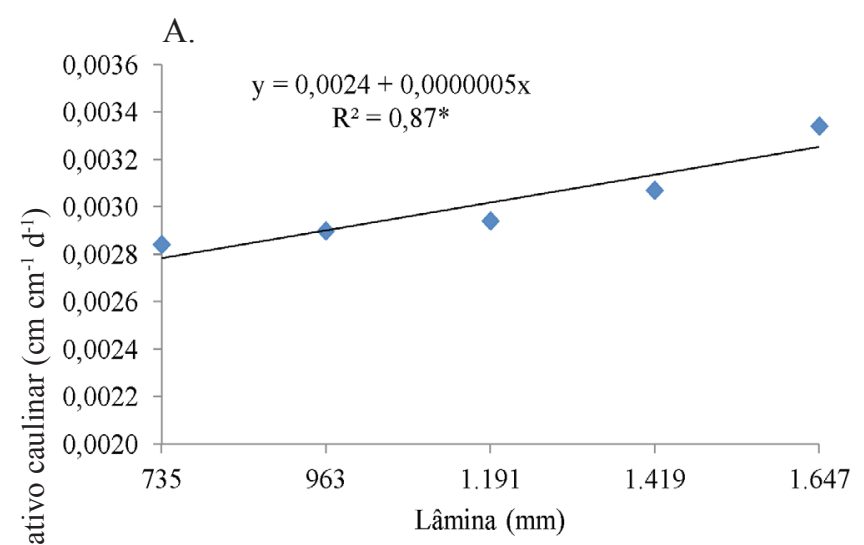

B.

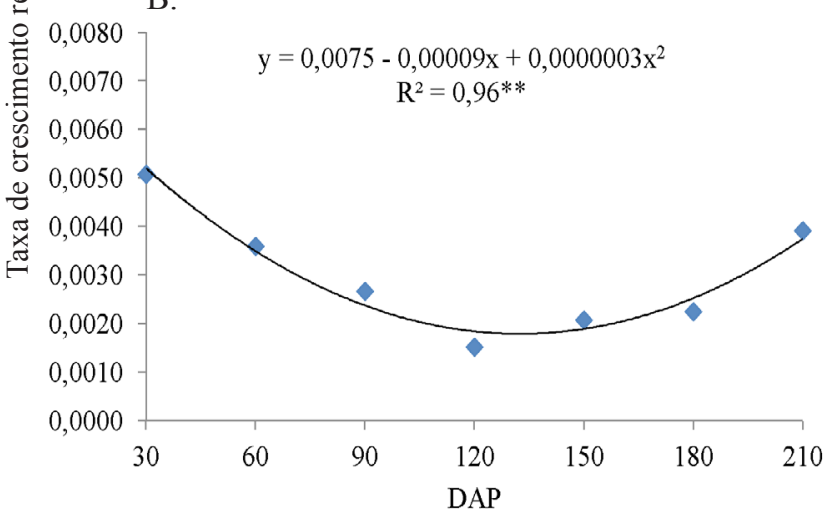

Figura 4. Taxa de crescimento relativo em altura caulinar do pinhão-manso, em função da lâmina total de água aplicada (A) e época de coleta (B)

significativas para as lâminas de água aplicadas não chegando, porém, a um ponto de máximo.

Observando de uma forma geral verifica-se que, aumentando a lâmina de menor volume aplicado durante o experimento ( 735 $\mathrm{mm})$ para a de maior volume $(1.647 \mathrm{~mm})$ obtém-se $124,08 \%$ de acréscimo de volume aplicado tomando-se como base que a taxa de crescimento relativo caulinar aumentou $17,59 \%$ na maior lâmina aplicada em relação à menor lâmina, pode-se deduzir que a cada percentual de lâmina acrescida equivale a um acréscimo de $0,142 \%$ no valor da taxa de crescimento relativo caulinar da cultura do pinhão-manso.

Tal tendência pode ser explicada pelo fato de que mesmo um estresse hídrico moderado é suficiente para desencadear a síntese de ácido abscísico (ABA), a partir dos carotenoides na raiz. Este ácido é, em seguida, transportado como um "sinal da raiz" para diferentes partes da planta, induzindo uma variedade de efeitos, dentre eles o provável retardamento do crescimento e desenvolvimento das plantas (Lacher, 2000).

$\mathrm{Na}$ análise de regressão da taxa de crescimento relativo em altura caulinar em relação à época de coleta de dias após poda de uniformização, verificou-se que o modelo polinomial de $2^{\circ}$ grau foi o que melhor se ajustou apresentando coeficiente de determinação de 0,96 (Figura 4B).

A época em que se obtiveram os maiores valores da taxa de crescimento relativo em altura caulinar do pinhão-manso foi aos $30 \mathrm{DAP}$, quando ocorreu a primeira coleta de dados após a poda de uniformização. Tal crescimento acentuado pode ser explicado pelo início da aplicação dos tratamentos com 
lâminas de irrigação bem como do surgimento de folhagem para a realização do processo fotossintético visto que, durante a poda, todas as plantas foram uniformizadas ao tamanho de $30 \mathrm{~cm}$ de altura, pois não apresentava folhas mas somente $\mathrm{o}$ caule da planta.

Durante o experimento ocorreram períodos em que os valores da taxa de crescimento relativo caulinar das plantas de pinhão-manso começaram a declinar, quando as plantas estavam com 90 DAP e se agravando aos 120 DAP; este declínio pode ser resultante dos fatores climáticos registrados na época: temperatura, umidade relativa do ar, velocidade dos ventos, evaporação do ar e precipitação (Tabela 4).

Segundo Saturnino et al. (2005) e conforme a região, o desenvolvimento inicial das mudas de pinhão-manso pode ser influenciado pela época de chuvas, ventos dominantes e outras ocorrências climáticas típicas de cada local.

Outro fator que pode explicar este declínio na taxa de crescimento relativo caulinar no período mencionado pode ser o fato que coincidiu com a floração e início da frutificação da cultura, em que Larcher (2000), afirma que paralisações no crescimento vegetativo em função da aceleração do crescimento produtivo ocorrem pela canalização da energia, de nutrientes e assimilados à floração e frutificação que, por sua vez, se originam no processo fotossintético, na incorporação de substâncias minerais e na mobilização de reservas para a formação e enchimento dos frutos.

Chaves et al. (2009) também verificaram, em pesquisa com pinhão-manso, que a taxa de crescimento em altura das plantas reduziu linearmente neste período. Lima Júnior (2011) também constatou, avaliando as características agronômicas no desenvolvimento inicial do pinhão-manso, que ao se aproximar o estádio reprodutivo as taxas de crescimento decaíram progressivamente tendo em vista que as plantas passam a direcionar os fotoassimilados para os órgãos reprodutivos. Resultado semelhante foi encontrado por Nery et al. (2009) que constataram o crescimento do pinhão-manso mais pronunciado até os 100 dias após a semeadura quando as plantas iniciaram o florescimento.

No que se refere à interação entre os fatores lâmina e época de coleta (L x E) houve um comportamento praticamente polinomial, semelhante ao comportamento com a época de coleta, quando a planta partiu de uma taxa de crescimento relativo elevada aos 30 DAP em todas as lâminas estudadas para uma grande depressão aos 120 DAP também em todas as lâminas estudadas.

As variações das taxas de crescimento relativo em altura caulinar do pinhão-manso com a aplicação das lâminas de água nas diferentes épocas de coleta de dados podem ser melhor visualizadas utilizando-se a metodologia da superfície de resposta (Figura 5), com a qual se observa que a maior taxa de crescimento relativo caulinar do pinhão-manso foi de 0,0059 $\mathrm{cm} \mathrm{cm}^{-1} \mathrm{~d}^{-1}$ com a lâmina aplicada de $1.646,61 \mathrm{~mm}$ aos 30 DAP e a menor taxa de crescimento relativo do pinhão manso foi de $0,0012 \mathrm{~cm} \mathrm{~cm}^{-1} \mathrm{~d}^{-1}$ com a lâmina de $1.191,07 \mathrm{~mm}$ aos 120 DAP

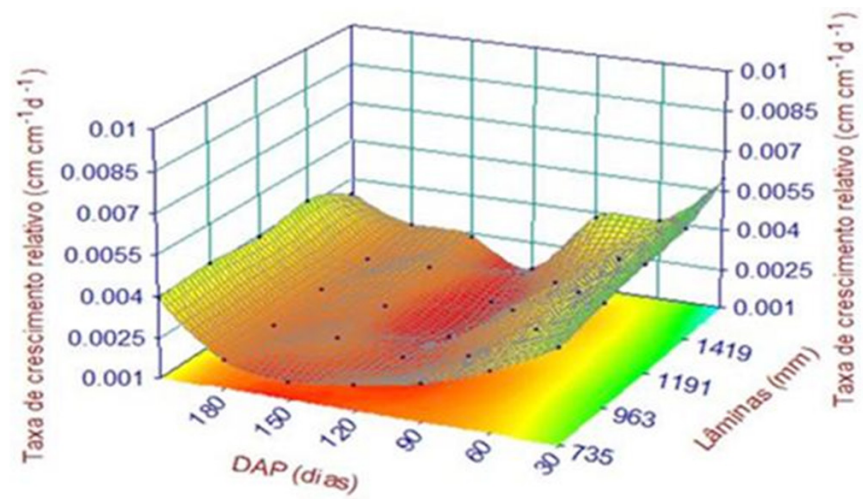

Figura 5. Taxa de crescimento relativo em altura caulinar do pinhão-manso, em função da interação da lâmina de água e época de coleta (DAP - dias após a poda de uniformização)

Esta variação dos valores da taxa de crescimento relativo em altura caulinar é justificada, segundo Lacher (2000) porque, no curso de seu desenvolvimento, as plantas se ajustam à periodicidade sazonal da radiação, duração do dia, temperatura e precipitação (quanto ao início e à quantidade). Portanto, o processo de transição de fase representa um ajuste no ciclo de vida da planta a períodos favoráveis e desfavoráveis do crescimento e a alternância do principal crescimento vegetativo; com a formação das flores e dos frutos é típico para as plantas perenes de latitudes elevadas e intermediárias e para regiões secas, embora este processo possa ocorrer também nos trópicos.

O outro aspecto é a questão da umidade do solo. A interação menor lâmina aplicada com a ocorrência das fases de floração e de frutificação proporcionou os menores valores da taxa de crescimento relativo em altura caulinar, fato este explicável devido ao evento de que, com a menor lâmina há, provavelmente, menor produção de fotoassimilidados, ao passo que nas fases de floração e de frutificação os fotoassimilados são preferencialmente direcionados para as flores e frutos, respectivamente; em consequência, com menor produção e menor direcionamento nessas condições ocorreram as menores taxas de crescimento caulinar.

Tabela 4. Valores médios, mínimos e máximos de temperatura do ar (T), umidade relativa do ar (UR), velocidade do vento $\left(U_{20 \mathrm{~m}}\right)$, evaporação $(\mathrm{mm})$ e precipitação $(\mathrm{mm})$ observado durante o período experimental (DAP)

\begin{tabular}{|c|c|c|c|c|c|c|c|}
\hline \multirow{2}{*}{ DAP } & Tméd & Tmin & Tmax & \multirow{2}{*}{$\begin{array}{c}\text { UR } \\
(\%)\end{array}$} & \multirow{2}{*}{$\begin{array}{c}\mathbf{U}_{2,0 \mathrm{~m}} \\
\left(\mathrm{~m} \mathrm{~s}^{-1}\right)\end{array}$} & Evaporação & Precipitação \\
\hline & & $\left({ }^{\circ} \mathrm{C}\right)$ & & & & \multicolumn{2}{|c|}{ (mm) } \\
\hline 30 & 22,78 & 20,50 & 28,63 & 80,47 & 2,97 & 219 & 73 \\
\hline 60 & 24,34 & 21,75 & 30,22 & 70,24 & 2,90 & 326 & 0 \\
\hline 90 & 25,90 & 23,00 & 31,82 & 60,01 & 2,83 & 254 & 10 \\
\hline 120 & 25,39 & 22,86 & 30,26 & 62,65 & 2,58 & 270 & 0 \\
\hline 150 & 25,70 & 22,72 & 30,59 & 62,70 & 2,40 & 260 & 0 \\
\hline 180 & 25,60 & 23,28 & 29,81 & 66,77 & 1,63 & 161 & 115 \\
\hline 210 & 25,47 & 23,61 & 28,21 & 77,41 & 0,93 & 227 & 82 \\
\hline Média & 25,03 & 22,53 & 29,93 & 68,61 & 2,32 & 245,29 & 40 \\
\hline
\end{tabular}


Foram geradas 401 equações para a superfície de resposta da taxa de crescimento relativo em altura caulinar do pinhãomanso, para os fatores lâminas aplicadas versus épocas de coleta. Entre as equações geradas foi selecionada a melhor equação polinomial de segundo grau com base no valor do coeficiente de determinação $\left(\mathrm{R}^{2}=0,90^{* *}\right)$ e a significância dos parâmetros componentes da Eq. 6:

$$
\begin{aligned}
\mathrm{z} & =0,0068743762^{* *}-0,0000861880 \mathrm{x}^{* *}+ \\
& +0,00000032463 \mathrm{x}^{2 * *}+0,0000005385 \mathrm{y}^{*}
\end{aligned}
$$

$(* *)$ - efeito significativo a 0,01 de probabilidade

$(*)$ - efeito significativo a 0,05 de probabilidade em que:

$\mathrm{z} \quad$ - taxa de crescimento relativo caulinar, em $\mathrm{cm} \mathrm{cm}^{-1} \mathrm{~d}^{-1}$

$\mathrm{x}$ - época de coleta de dados (DAP), em dias

y - lâmina aplicada, em mm

O coeficiente de determinação encontrado para a equação acima foi igual a 0,90 indicando alto grau de associação entre a interação das lâminas aplicadas com as épocas de coleta da altura caulinar das plantas de pinhão-manso.

O resultado da análise de variância contido na Tabela 3 demonstra significância estatística em níveis de 0,01 de probabilidade para a variável taxa de crescimento absoluto e relativo em diâmetro caulinar do pinhão-manso para o fator época de coleta.

Quanto à análise de regressão da taxa de crescimento relativo em diâmetro caulinar em relação à época de coleta, verificou-se que o modelo polinomial de $2^{\circ}$ grau foi o que melhor se ajustou apresentando coeficiente de determinação de 0,73 (Figura 6).

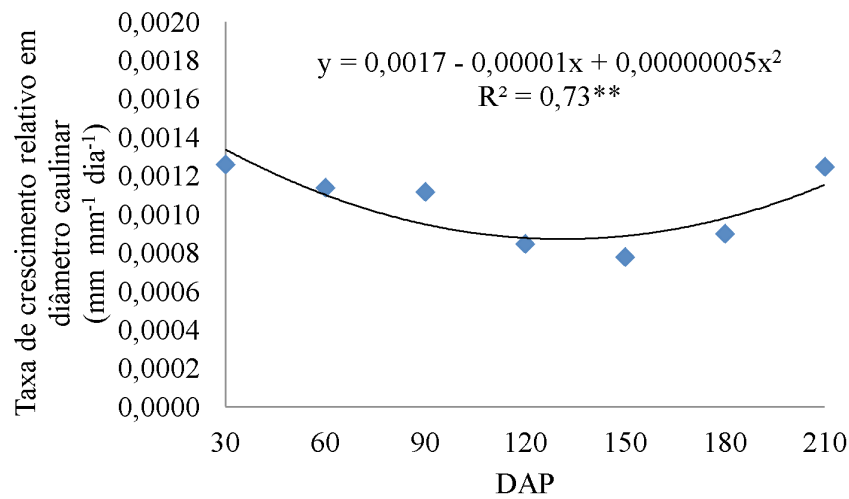

Figura 6. Taxa de crescimento relativo em diâmetro caulinar do pinhão-manso, em função da época de coleta (DAP - dias após a poda de uniformização)

O período que obteve os maiores valores da taxa de crescimento relativo em diâmetro caulinar do pinhão-manso foi aos $30 \mathrm{DAP}$, com $0,00126 \mathrm{~mm} \mathrm{~mm}^{-1} \mathrm{~d}^{-1}$, ocorrendo a primeira coleta de dados após a poda de uniformização e aos 210 DAP, com $0,00125 \mathrm{~mm} \mathrm{~mm}^{-1} \mathrm{~d}^{-1}$, em que a última coleta de dados foi realizada após a colheita do pinhão-manso. $\mathrm{O}$ maior valor durante os primeiros 30 dias após poda pode ser explicado pelo fato de que logo após a poda e com o início da aplicação das lâminas de irrigação e de adubação nitrogenada as plantas de pinhão-manso necessitaram "ganhar" volume em altura e em diâmetro para aumentar a área foliar e as taxas fotossintéticas. Com o aumento das taxas fotossintéticas em termos absolutos, uma quantidade maior de fotoassimilados foi disponibilizada para o crescimento caulinar. Abordagem similar sobre o crescimento inicial das plantas foi realizada por Lacher (2000).

No que se refere ao elevado valor da taxa de crescimento relativo em diâmetro caulinar do pinhão-manso encontrado aos 210 DAP, última coleta de dados do experimento, pode ser explicado pela retomada do crescimento vegetativo decorrente do fim da fase reprodutiva da planta, quando a mesma deixou de canalizar energia, nutrientes e assimilados para a formação e enchimento de frutos, retomando seu crescimento.

No que se refere à interação entre os fatores lâmina e época de coleta $(\mathrm{Lx}$ E) houve um comportamento praticamente polinomial, com alguns picos isolados de taxa de crescimento ocorrendo aos 30 DAP com lâmina de $963,30 \mathrm{~mm}\left(0,0017 \mathrm{~mm} \mathrm{~mm}^{-1} \mathrm{~d}^{-1}\right), 90$ DAP com lâmina de $1.191,07 \mathrm{~mm}\left(0,0016 \mathrm{~mm} \mathrm{~mm}^{-1} \mathrm{~d}^{-1}\right)$ e 210 DAP com lâmina de 735,53 mm $\left(0,0016 \mathrm{~mm} \mathrm{~mm}^{-1} \mathrm{~d}^{-1}\right)$.

As variações das taxas de crescimento relativo em diâmetro caulinar do pinhão-manso com a aplicação das lâminas de água nas diferentes épocas de coleta de dados são melhor visualizadas utilizando-se a metodologia da superfície de resposta (Figura 7).

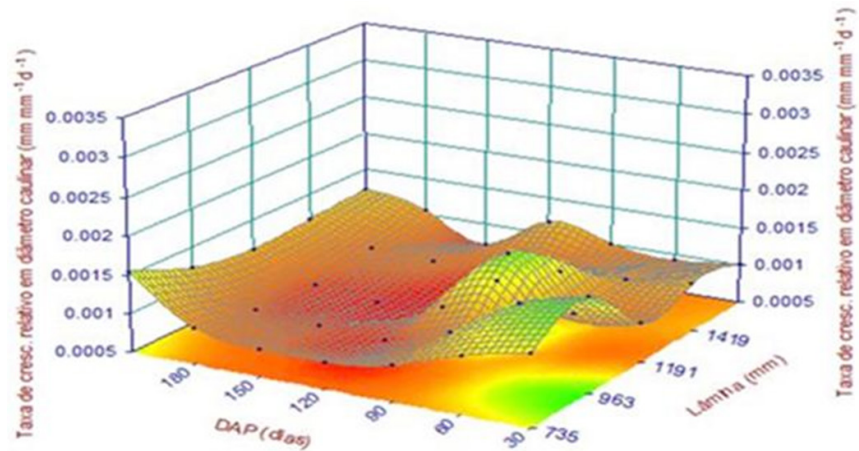

Figura 7. Taxa de crescimento relativo em diâmetro caulinar do pinhão-manso, em função da interação lâmina de água e época de coleta (DAP - dias após a poda de uniformização)

As menores taxas de crescimento relativo em diâmetro caulinar foram encontradas praticamente para todas as lâminas durante as épocas 120 e 150 DAP, obtendo-se valores compreendidos entre 0,0007 e $0,0008 \mathrm{~mm} \mathrm{~mm}^{-1} \mathrm{~d}^{-1}$ explicável devido ao fato de que nas fases de floração e frutificação os fotoassimilados são preferencialmente direcionados para as flores e frutos, respectivamente, em detrimento do crescimento caulinar.

A equação selecionada para taxa de crescimento relativo em diâmetro caulinar para os fatores lâminas aplicada versus época de coleta foi:

$$
\begin{aligned}
& \mathrm{z}=0,0025791983^{* *}-0,0000148713 \mathrm{x}^{* *}- \\
& -0,0000011608 \mathrm{y}^{\mathrm{ns}}+0,000000046433356 \mathrm{x}^{2 * *}+ \\
& +0,00000000030807538 \mathrm{y}^{\mathrm{ns}}+0,0000000022823515 \mathrm{xy}^{\mathrm{ns}}
\end{aligned}
$$


em que:

$\mathrm{z} \quad$ - taxa de crescimento relativo em diâmetro caulinar, em $\mathrm{mm} \mathrm{mm}^{-1} \mathrm{~d}^{-1}$

$\mathrm{x} \quad$ - época de coleta de dados (DAP), em dias

y - lâmina aplicada, em mm

Com base nos resultados obtidos da análise de variância apresentados na Tabela 3 observa-se efeito significativo da época de coleta dos dados (E) para as taxas de crescimento relativo em fitomassa fresca epígea. Os coeficientes de variação para os três fatores foram considerados elevados porém podem ser justificados pelo fato de envolver épocas de coletas e crescimento da planta.

$\mathrm{Na}$ análise de regressão da taxa de crescimento relativo em fitomassa fresca epígea do pinhão-manso em relação à época de coleta de dias após poda de uniformização, verificou-se que o modelo polinomial de $2^{\circ}$ grau foi o que melhor se ajustou apresentando coeficiente de determinação de 0,86 (Figura 8).

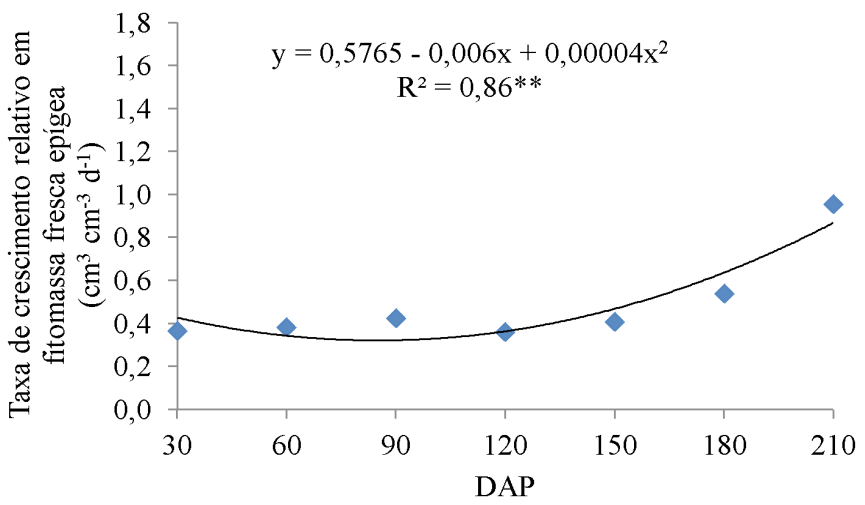

Figura 8. Taxa de crescimento relativo em fitomassa fresca epígea do pinhão-manso, em função da época de coleta (DAP - dias após a poda de uniformização)

Durante o período do experimento a taxa de crescimento relativo em fitomassa fresca epígea do pinhão-manso se manteve praticamente constante nos períodos de 30, 60, 90, 120 e 150 DAP, cujas taxas alcançadas foram de $0,37,0,38$, $0,43,0,36$ e $0,41 \mathrm{~cm}^{3} \mathrm{~cm}^{-3} \mathrm{~d}^{-1}$. A partir de 180 DAP a TCRFFE começou a se diferenciar em forma crescente $\left(0,54 \mathrm{~cm}^{3} \mathrm{~cm}^{-3}\right.$ $\mathrm{d}^{-1}$ ) representando, para este período, um acréscimo de $38,59 \%$ em relação à média dos valores obtidos dos 30 aos 150 DAP e chegando ao valor máximo aos $210 \operatorname{DAP}\left(0,96 \mathrm{~cm}^{3} \mathrm{~cm}^{-3} \mathrm{~d}^{-1}\right)$ obtendo-se um acréscimo de $161,46 \%$ em relação à média dos valores obtidos no mesmo período (Figura 8).

A formação de flores e frutos em abundância está, portanto, em competição com o crescimento vegetativo e removendo as reservas que poderiam ser usadas na renovação das gemas e no consequente crescimento das plantas (Lacher, 2000); observa-se, na Figura 8, um acréscimo acentuado nas taxas de crescimento em fitomassa fresca epígea do pinhão-manso aos 180 e 210 DAP coincidindo com uma floração menor e formação de frutos, retomando o crescimento vegetativo.

\section{ConClusõEs}

1. A altura caulinar aumentou linearmente com a adição de lâminas de água alcançando valores máximos com a maior lâmina na última época de coleta de dados.
2. A época de coleta influenciou os valores de altura tanto quanto o diâmetro caulinar obtendo-se comportamento linear no decorrer da condução do experimento.

3. As doses de adubação nitrogenada utilizadas neste experimento não influenciaram significativamente nenhuma das variáveis avaliadas.

4. As taxas de crescimento relativo caulinar obtiveram comportamento linear e crescente com o incremento nas lâminas aplicadas.

5. Ocorreu declínio nos valores da taxa de crescimento relativo em altura e diâmetro caulinar, causado, provavelmente, pelos fatores climáticos e devido ao início da floração e da formação de frutos.

\section{Literatura Citada}

Albuquerque, W. G. de; Freire, M. A. de O.; Beltrão, N. E. de M.; Azevedo, C. A. V. de. Avaliação do crescimento do pinhão-manso em função do tempo, quando submetido a níveis de água e adubação nitrogenada. Revista de Biologia e Ciências da Terra, v.9, p.68-73, 2009.

Arruda, F. P. de; Beltrão, N. E. de M.; Andrade, A. P. de; Pereira, W. E.; Severino, L. S. Cultivo de pinhão-manso (Jatropha curca L.) como alternativa para o semi-árido nordestino. Revista Brasileira de Oleaginosas e Fibrosas, v.8, p.789799, 2004.

Chaves, L. H. G.; Cunha, T. H. C. da S.; Barros Junior, G.; Lacerda, R. D.; Dantas Junior, E. E. Zinco e cobre em pinhão-manso. 1. Crescimento inicial da cultura. Revista Caatinga, v.22, p.94-99, 2009.

Faria, M. A. de; Evangelista, A. W. P.; Melo, P. C. de; Alves Júnior, J. Resposta da cultura de pinhão-manso à irrigação e à adubação com OMM-Tech. Irriga, v.16, p.70-81, 2011.

Lacerda, R. D. de; Guerra, H. O. C.; Barros Júnior, G. Influência do déficit hídrico e da matéria orgânica do solo no crescimento e desenvolvimento da mamoneira BRS 188 - Paraguaçu.Revista Brasileira de Ciências Agrárias, v.4, p.440-448, 2009.

Laime, E. M. O.; Freire, E. de A.; Veras, R. P.; Fernandes, P. D.; Oliveira, D. C. de S.Desenvolvimento de pinhãomanso em função de diferentes lâminas de irrigação com água superficial poluída. Revista Educação Agrícola Superior, v.24, p.107-111, 2009.

Larcher, W. Ecofisiologia vegetal. Tradução: Prado, C. H. B. A. São Carlos: RIMA, 2000. 531p.

Laviola, B. G.; Dias, L. A. S. Teor e acúmulo de nutrientes em folhas e frutos de pinhão-manso. Revista Brasileira de Ciência do Solo, v.32, p.1969-1975, 2008.

Lima Júnior, L. A. de. Crescimento inicial do pinhão-manso em função de suspensões hídricas e doses de potássio. Fortaleza: UFC. 2011. 59p. Dissertação Mestrado

Nery, A. R.; Rodrigues, L. N.; Silva, M. B. R.; Fernandes, P. D.; Chaves, L. H. G.; Dantas Neto, J.; Gheyi, H. G. Crescimento do pinhão-manso irrigado com águas salinas em ambiente protegido. Revista de Brasileira de Engenharia Agrícola e Ambiental, v.13, p.551-558, 2009. 
Oliveira, I. R. S. de; Oliveira, F. N. de; Medeiros, M. A. de; Torres, S. B.; Teixeira, F. J. V. Crescimento inicial do pinhão-manso (Jatropha curcas) em função da salinidade da água de irrigação. Revista Caatinga, v.23, p.40-45, 2010.

Oliveira, S. J. C.; Beltrão, N. E. de M. Crescimento do pinhão-manso (Jatropha curcas) em função da poda e da adubação química. Revista Brasileira de Oleaginosas e Fibrosas,v.14, p.9-17, 2010.

Ratree, S. A. Preliminary study on physic nut Jatropha curcas in thailand. Journal of Biogical Sciences, v.7, p.16201623, 2004.

Roza, F. A. Alterações morfofisiológicas e eficiência de uso da água em plantas de Jatropha curcas L. submetidas à deficiência hídrica. Ilhéus: UESC. 2010. 67p. Dissertação Mestrado
Santos, C. M. dos. Fenologia e capacidade fotossintética do pinhão-manso (Jatropha curcas L.) em diferentes épocas do ano no estado de Alagoas. Rio Largo: UFA. 2008. 79p. Dissertação Mestrado

Saturnino, H. M.; Pacheco, D. D.; Kakida, J.; Tominaga, N.; Gonçalves, N. P. Cultura do pinhão-manso (Jatrofa curcas L.). Informe Agropecuário, v.26, p.44-78, 2005.

Silva, M. B. R. da; Dantas Neto, J.; Fernandes, P. D.; Farias, M. S. S. de. Cultivo de pinhão- manso sob condições de estresse hídrico e salino, em ambiente protegido. Revista de Biologia e Ciências da Terra, v.9, p.74-79, 2009a.

Silva, M. B. R.; Nery, A. P.; Fernandes, P. D.; Dantas Neto, J.; Lima, V. L. A. de; Viégas, R. A. Produção do pinhão-manso, primeiro ano, irrigado com água residuária. In: Congresso Brasileiro de Pesquisas de Pinhão-manso, 1, 2009, Brasília. Anais... Brasília: MCT, 2009b. CD-Rom 